\title{
INDIVIDUAL AND CONFLICT: A SOCIOLOGICAL ANALYSIS OF PERSONAL CHARACTERS LEADING TO CONFLICT FORMATION AMONG THE PAKHTUNS OF KHYBER PAKHTUNKHWA, PAKISTAN
}

\author{
Riaz Ahmad \\ Research Scholar \\ Shaheed Benazir Bhutto University \\ Benazirabad - Pakistan \\ riaz@sbbu.edu.pk \\ Dr. Adnan Khan \\ Assistant Professor \\ Department of Sociology \\ University of Malakand \\ Malakand - Pakistan \\ akhan@uom.edu.pk
}

\begin{abstract}
Development of society and its inhabitants is negatively affected by prevailing conflicts. Although, enormous research and theoretical work regarding macro level factors leading to conflict formation is available, still, research is needed to investigate the problem at individual level. The current study aims at finding out personal characters resulting in conflict formation. For this cross sectional qualitative study, data were collected from participants through interview guide. As, totality of the personality characters of individual cannot be negative or anti-social, therefore, the current study aimed at finding out negatively interacting characters which frequently ends in conflict formation. The study found that, incongruous modes of interaction, egocentrism, bad attitude, negative personal tendencies, ideological differences, psychological problems, and personality disorder; were the most common characters of personality that not only had negative effects on cognitive abilities of individuals rather jolt negative energies in their behavior and led to conflict formation. Furthermore, the study suggests that many conflicting situations in our daily lives could be avoided if we leash these negative personality
\end{abstract}




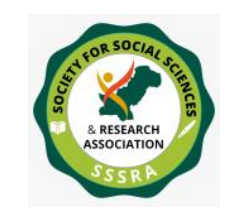

Pak. Journal of Int'L Affairs, Vol 4, Issue 3 (2021) Individual and conflict: a sociological analysis ...

characters and keep focusing on reforming and redirecting our behavior. For this purpose, further research is needed to find out ways and techniques which could replace negative personality characters by positive ones to ensure peacebuilding.

Keywords: Conflict formation, Personality characters, Khyber Pakhtunkhwa.

\section{Introduction}

Human behavior is not a spontaneous flow of energies, rather, it expresses how individual got socialized, how his natural propensities are, and what kind of personality characteristics he possesses. Although, some actions and reactions are incidental without any personal intent of the participants, still, other involve personal choices and inclinations. Same way, conflict tendencies are outcomes of either problems in individual's socialization, personality or incompatible cognitive processes due to psychological abnormalities (Miller, 1948). The current research study was undertaken to probe out individual's personal characters and their manifestation that lead to conflict formation. Moreover, it would help educate the readers regarding behavior patterns that shatter peace among people and create negative social relations. The present study is an endeavor to fill the gap of identifying individual level factors in conflict formation as against the previous research works done by psychologists and social scientists on macro level.

Barash and Webel view conflict as 'a disagreement or incompatibility of goals, values and status that occurs between individuals or groups' (Barash \& Webel, 2002). More specifically, it is an output, a process or a way of communication involving emotional and social aspects: where the emotional side indicates inner self of the participants, and the social aspect derives from the behavior (Miller, 1948: Pawlak, 1998), which affect individual and group achievements positive or negatively (Deutsch, 1973; Chuang \& Tzy-Ning, 2003; Ilies, Judge, \& Keeney, 2011).

Conflict ranges from simple differences of opinion to disagreement, discord, acerbities, and violence that may get intensified if not properly handled (Elmagri \& Eaton, 2011). Interactionist perspective views conflict as a healthy social process because it transforms social structure and functions if solved effectively. The behaviorist approach adds that, conflict is an inevitable phenomenon and is both useful and harmful for society and its inhabitants. But then, due to the involvement of hostile intentions, conflict in individual or group capacity is considered an abnormal activity that not only disturbs standard social relations, rather, hampers normal growth of society and poses threat to peace and order around (Jehn \& Bendersky 2003). 


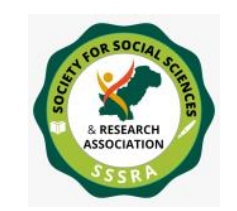

Pak. Journal of Int'L Affairs, Vol 4, Issue 3 (2021) Individual and conflict: a sociological analysis ...

\begin{abstract}
Although, anything might cause conflict; ranging from simple differences of opinion to material possession (Bendersky \& Hays 2012), yet, the aggressive behavior during conflict is the upshot of mindset, understanding and inclinations of the participants (Fathali \& Rom, 2010). Research studies indicate that, human behavior is guided and directed by mind and cognitive processes like thinking, knowing, remembering, judging and perception (Wilson \& Hanna, 1993), therefore, initiation of conflict involves a number of factors from participants including psychosomatic, illusion, unfavorable experience and behavior problems, malfunctioning and incognizant to possible outcomes of the conflict (Behfar, Peterson, Mannix, \& Trochim 2008). Besides, during social interaction process, contradictory values and situations create tension relationship among participants because of incompatibility in goal-achievement (Chuang \& Tzy-Ning, 2003; Dreu \& Weingart, 2003), which might be the cogent choice for one's self and may go against social development. (Jehn and Bendersky, 2003)
\end{abstract}

A social situation either normal or otherwise is determined by uniformities or differences in culture, attitudes, values, perceptions and awareness (George \& Jones, 1997: Hermann, Jacobson, \& Moffat, 1999). Differences of the type are termed by Fisher as personality conflict and refers to very strong differences in motives, values or styles in dealing with people that are not resolvable. Unresolved power conflict usually recycles and escalates to the point of relationship breakdown and termination (Fisher, 2000).

Baron judges individual's personal development from their expression of politeness and decency during communication process and courtesy in social relations with others (Baron, 1990). In this regard, studies reveal that, inappropriate modes of communication like unapproved communication patterns, showing anger, authoritarianism and misinformation are responded with intolerance and relentlessness that may deteriorate normalcy of the situation and arise conflict among individuals (Hotepo, Asokere, Azeez, \& Ajemunigbohun, 2010).

\title{
Objectives of the Study
}

The study was carried out under the following objectives:

- To analyze individual's personal characters that result in conflict formation.

- To explore, how psychological problems cause conflicting tendencies in individual.

- To investigate, how personality disorder lead to conflicting behavior.

\section{Research Design}




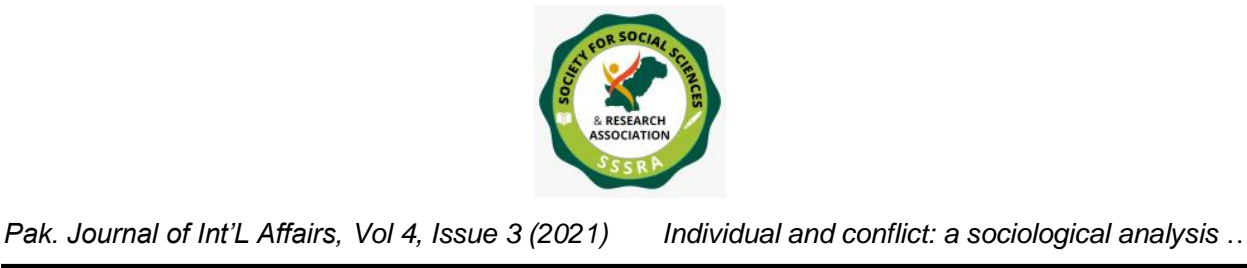

The current research study having qualitative nature, adopted a cross-sectional design and descriptive model to investigate the problem under consideration. The study was carried out in District Swat, Khyber Pakhtunkhwa, Pakistan. Swat district consists of 7 tehsils (administrative units), with rural and urban areas in its geographic distribution. To depict thorough picture of the problem, views and responses of participants from all the seven tehsils were collected.

\section{Population and Sampling Design}

The study group comprised of 42 participants, which included 6 participants from each tehsil. To depict thorough picture of the problem, purposive sampling technique was demonstrated, where only male adults with different socio-economic and demographic characters i.e. educated, uneducated, employed, unemployed, social status, family type, geographic distribution and age group were included in the study.

\section{Data Collection Methods and Analysis}

Data were collected from the participants during face to face interviews, using semi structured interview guide. Ethics of research were carefully observed before undertaking the interviews. Purpose and goals of the study were discussed with the respondents, and their permission were sought before undertaking interviews. Moreover, they were assured of the confidentiality of their personal information. Later on, the data collected were thematically analyzed and fair descriptions were made to present it to readers. 
Table \# 1 Demographic characteristics of the participants

Characteristics

Gender

1. Male

Age

1. 20-29

2. $30-39$

3. $40-49$

4. $50-59$

Geographic distribution

1. Rural

2. Urban

Social class

1. Lower

2. Middle

3. Upper

Educational status

1. Educated

2. Uneducated

Qualification, if educated

1. Matriculation

2. Intermediate

3. College graduation

4. Post-graduation

Family structure

1. Joint

2. Extended

3. Nuclear

Marital status

1. Unmarried

2. Married

Employment status

1. Unemployed

2. Employed

Type of occupation

1. Government servant

2. Semi-government servant

3. Self-employed

4. Any other
Frequency (\%)

42(100)

09(21.42)

17(40.47)

12(28.57)

04(9.52)

24(57.14)

18(42.85)

17(40.47)

$21(50)$

$4(9.52)$

37(88.09)

$5(11.90)$

6(16.21)

$7(18.91)$

15(40.54)

9(24.32)

8(19.04)

13(30.95)

21(50)

11(26.19)

31(73.80)

14(33.33)

28(66.66)

9(32.14)

13(46.42)

4(14.28) 


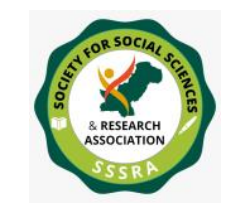

Pak. Journal of Int'L Affairs, Vol 4, Issue 3 (2021)

Individual and conflict: a sociological analysis ...

\section{Figure.1 Exploring self-Perceived Reason behind Recently Experienced Conflict}

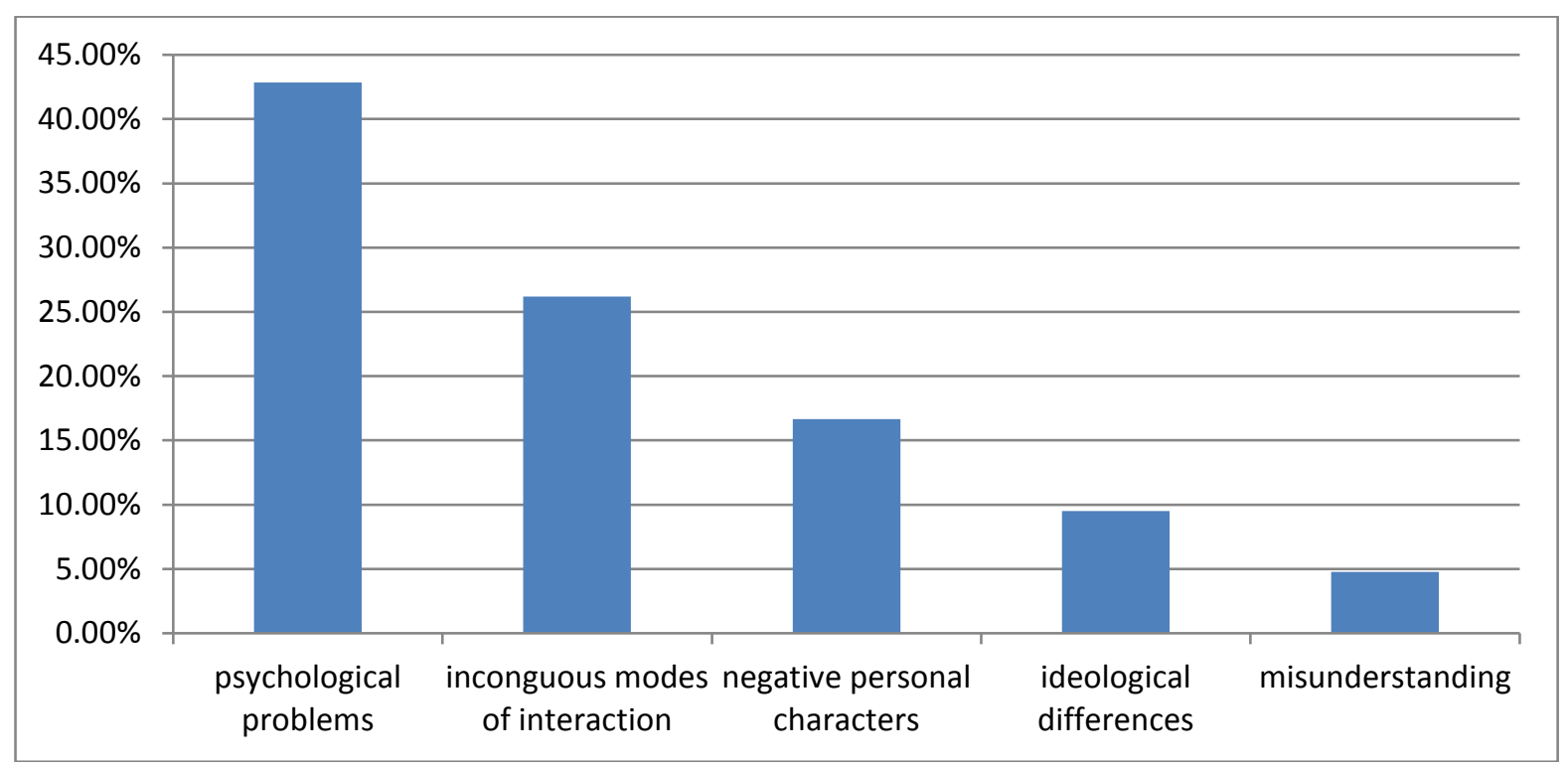

Figure. 1 demonstrates factors and characteristics that the participants perceived as conflict triggering agents in their personally experienced cases of conflicts. The participants expressed that, two in every fifth conflicts $(42.85 \%)$ were due to psychological problems and their associated unwanted outcomes. Some $1 / 4^{\text {th }}$ of the conflicts $(26.19 \%)$ were due to incongruous modes of interaction and their negative effects on social relations. One in every sixth conflicts $(16.66 \%)$ were due to negative personal characters that worked as threat to people around. One in tenth of the conflicts (9.52\%) were because of ideological differences, and one in twentieth conflicts $(4.76 \%)$ was due to misunderstanding that arose either due to communication or understanding problems.

\section{Demographic Findings Related to Conflict Formation}

32 participants from the study group expressed that, urban areas observed more conflicts than rural areas, mainly because of dispositional differences which existed due to diverse nature of population in urban area $53.12 \%$, problems in personal understanding due to less primary relations in urban areas $25 \%$, behavior differences which existed because of cultural variability $18.75 \%$, complex life style with lesser space for others $3.12 \%$.

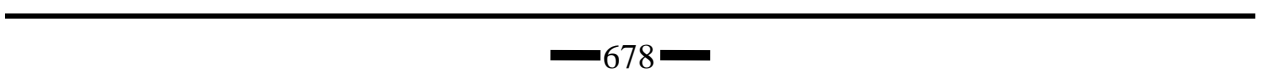




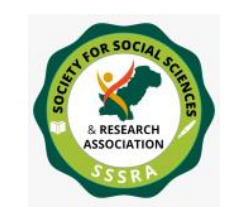

Pak. Journal of Int'L Affairs, Vol 4, Issue 3 (2021) Individual and conflict: a sociological analysis ...

26 participants revealed that, uneducated people were more vulnerable to conflict formation than educated people, and that was because they practiced rough communication patterns $42.30 \%$, rigidity in behavior $23.07 \%$, intolerance $23.07 \%$, less civility $19.23 \%$, and less control on aggression $15.38 \%$.

28 participants indicated that, unemployed people had greater evidences of initiating conflict as compared to employed ones, because they had more time and occasions to contact anti-social elements of society $64.28 \%$, kept bad company $14.28 \%$, interrupted in other's works $14.28 \%$, and were inclined to criminal pursuits due to stress $7.14 \%$.

37 participants stated that, as compared to married people, unmarried individuals had greater indications of conflict formation. It was because they possessed less stable emotions and behavior $78.37 \%$, were less aware of the challenges of life $13.51 \%$, and spent more time outside home predominantly with unsocial people $8.10 \%$.

33 participants demonstrated that, individuals in the age group 20-25 were more inclined to conflict formation than others, because they were energetic $51.51 \%$, less sensible $36.36 \%$, had lesser control over aggression $36.36 \%$, and possessed less serious approach to life $12.12 \%$.

\section{Results}

39 participants indicated that, incongruity in modes of interaction arose conflict among people. Incongruous modes were further specified as: using vulgar words during communication $82.05 \%$, violating others' privacy $79.48 \%$, misinformation or withheld information $71.79 \%$, interfering in others' works $53.84 \%$, slangs $43.58 \%$, spreading rumors $30.76 \%$, disclosing others' private information $30.76 \%$, aggressive tone during conversation $28.20 \%$, distorting information $23.07 \%$, authoritarian mode during communication $20.51 \%$, and misinterpreting others' message $15.38 \%$.

37 participants in the study group demonstrated that, egocentric personalities were more exposed to conflict. Behavior outcomes of egocentrism included inability to adjust in different social situations $78.37 \%$, distinct mindset and actions than those of the people around $72.97 \%$, unsocial behavior $67.56 \%$, avoiding social obligations $64.86 \%$, sense of supremacy over others $59.45 \%$, not as much of consideration for others $54.05 \%$, disregarding others' stance $54.05 \%$, inability to work in team $45.94 \%$, and fewer inclination to fulfil others' needs $43.24 \%$.

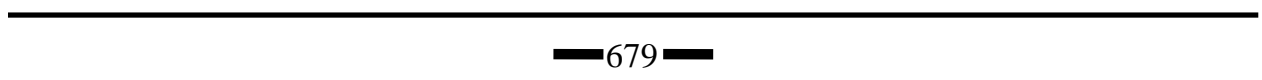




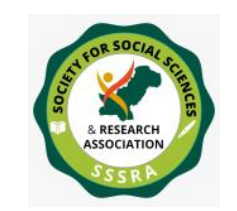

Pak. Journal of Int'L Affairs, Vol 4, Issue 3 (2021) Individual and conflict: a sociological analysis ...

35 participants viewed that, bad attitude of individual affected his behavior in family, work-place and in social life that in response arose negative energies in others leading to conflict formation. Behavior manifestation of bad attitude included harsh conduct $77.14 \%$, unharmonious communication patterns $71.42 \%$, feeling of stress $68.57 \%$, adjustment problems $68.57 \%$, declined team work tendencies $65.71 \%$, negative thoughts and actions $65.71 \%$, lack of professionalism $54.28 \%$, lack of tolerance $48.57 \%$, lack of compatibility with others $45.71 \%$, and lack of care for others $45.71 \%$.

36 participants expressed that, negative personal tendencies in individual created a sense of discomfort and insecurity in others and leading to conflict formation. Negative personal tendencies and their unwanted outcomes included keeping bad company $91.66 \%$, discourteous conversation patterns $88.88 \%$, cheating others $86.11 \%$, intervening in others' matters $83.33 \%$, being disrespectful $80.55 \%$, criminality $80.55 \%$, aggressive disposition $69.44 \%$, negative thoughts and actions $61.11 \%$, drug addiction $58.33 \%$, being intolerant $55.55 \%$, arrogance $50 \%$, aggravating minor matters of despise $50 \%$, theft $50 \%$, telling lie $47.22 \%$, spreading rumors $47.22 \%$, illegal sexual relations $41.66 \%$, selfishness $38.88 \%$, and dominating others $36.11 \%$.

32 participants demonstrated that, ideological differences in a less advanced social and cultural set up produced weak intellectual capabilities and uncontrolled actions in followers that might end in conflict. Factors instigating conflict out of such differences included: publicly disrespecting opposing views $84.37 \%$, speaking ill of others' leadership $78.12 \%$, spreading propaganda to weaken opponent party $75 \%$, unduly criticizing opponents $65.62 \%$, attempt to undermine others' ideological belongings $59.37 \%$, and defaming opposite ideologies $37.5 \%$.

40 participants revealed that, psychological problems (frustration, tension and anxiety) brought about negative changes in mind and behavior of individual which disturbed his relations with others. Upshots of such changes included angry disposition 90\%, loss of control over one's self $90 \%$, least participation in familial obligations $80 \%$, rudeness in behavior $72.5 \%$, avoiding social obligations $72.5 \%$, violent tendencies $60 \%$, feeling of insecurity $57.5 \%$, criminal tendencies $57.5 \%$, sexual harassment $55 \%$, taking things very seriously $52.5 \%$, and associated social aspects like calling one insane, abnormal or mad $52.5 \%$.

All participants in the study group indicated that, personality disorder contributed in conflict formation more than any other factor. Consequences of personality disorder which led to conflict formation included uncontrolled aggression $95.23 \%$, harsh behavior $88.09 \%$, pessimism $80.95 \%$, undetermined attitude $76.19 \%$, inconsistent behavior $69.04 \%$, suspecting others $69.04 \%$, feeling of hatred towards all around $66.66 \%$, corporal 


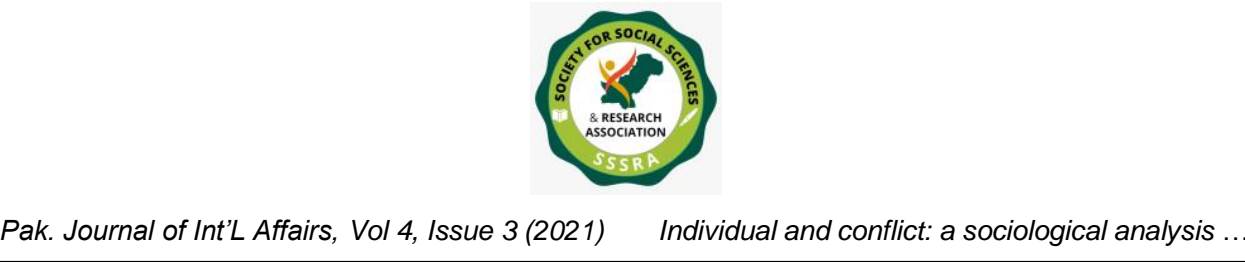

violence in family $64.28 \%$, sexual abuse $59.52 \%$, seeking illegal means for every felt need $59.52 \%$, mistrust on people $57.14 \%$, vindictive $45.23 \%$, being violent $42.85 \%$, less care for social standards $38.09 \%$, greater expectations and very few performance $38.09 \%$, jealousy $38.09 \%$, lack of cooperation $35.71 \%$, exceed personal limits $35.71 \%$, and feeling of negativity in every social relation $26.19 \%$.

\section{Discussion and Conclusion}

The current study focused on personality characteristics and tendencies of individual which contributed in conflict formation. Keeping in mind subjective nature of the study, responses were sought specifically about those characters of individual personality that directly or indirectly resulted in conflict formation. Seven characters of individual personality that most frequently were observed the triggering force in conflict formation among Pakhtuns of Khyber Pakhtunkhwa included: 1. Incongruous modes of interaction, 2. Egocentrism, 3. Bad attitude, 4. Negative personal tendencies, 5. Ideological differences, 6. Psychological problem, and 7. Personality disorder.

Interaction is an essential mean for meeting human needs and bridging gaps among people; however, incongruous interaction patterns rather broaden the gaps and create negative social relations. As inappropriate modes of interaction predominantly contain elements of disrespect or infringing others' privacy or misguiding therefore, it is considered as a threat to one's self-esteem and integrity and is responded with harshness and intolerance which arise conflicting tendencies. The results are supported by secondary data which revealed that, conflict arises when incongruous modes of interaction negatively affect a normal social situation and abnormal way of behavior interplay among the participants (Baron, 1990: Hotepo., Asokere., Azeez., \& Ajemunigbohun, 2010).

Egocentrism is an impaired aspect of individual's personality mainly because it negatively effects abilities and capabilities of the person and bring about considerable change in attitude and behavior with which he finds it harder to get adjusted in different social situations. Apart from it, the negative responses that such people get from the people around are due to socially constructed negative image of the person because of his unapproved behavior and lack of participation in social obligations. Miller in his famous work 'Classics in the history of psychology' expressed that, human behavior is the expression of cognitive processes; whereas, individuals with cognitive disabilities approach objects and views from very different orientations (Miller, 1948), which create strong differences in motives, values or styles during public interaction that Fisher termed as personality conflict (Fisher, 2000). 


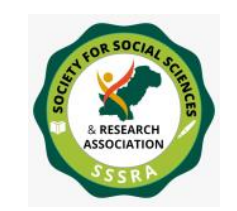

Pak. Journal of Int'L Affairs, Vol 4, Issue 3 (2021) Individual and conflict: a sociological analysis ...

Attitude formation and change depends on mind and mental processes that guides and directs human behavior. In line with the aforementioned statement (Miller, 1948), bad attitude affects internal and external energies of a person which are accompanied by some unwanted expressions like harshness in dealing, indecent communication patterns and least participation in communal practices. Additionally, person with bad attitude experiences stress, because of people around who usually do not care for such person and possess similar bad attitude toward him(Rahim, 2000), eventually the person does not keep continue social relations. Bad attitude, predominantly is an outcome of thinking debility which further affects mental compatibility of the person and arises intolerant and aggressive behavior tendencies which get responses and tendencies of the kind from others and enhance the chances of conflict formation.

Negative personality characters and tendencies in individual create sense of insecurity in others which is considered a permanent menace to their lives and properties. The present study found, that internalized negative personal characters either because of socialization problems or impacts of alike environment when interact with others create disharmony in social situations because of its negative impacts on the well-being of others as well as that of society. Secondary data in this regard indicates that, conflict stems from within individual, when the personal propensities of individual pose threat to the rights and liberties of others (Ilies, Johnson, Judge, \& Keeney, 2011; Williams, 2011).

Ideological differences do not lead to conflict in the sense that opposing ideologies intersect each other's views and interests, rather the outcomes of irrational behavior of patronage as well as of followers intend to damage ideological belongings of one another that is considered a threat to their identity. Fisher asserted that incompatibility in patterns of behavior, the preferences and ideologies, principles and practices that people believe in are driving forces for human actions and produce confrontations and violence (Fisher, 2000).

The current study found that, psychological problems enormously effect biological, physiological, mental and social well-being of a person, which has negative effects on his understanding of the world around and those of people and their actions. Moreover, because of misinterpreting a social situation and others' behavior, and due to loss of control over his emotions, anger and eventually that of behavior the person resort to violent actions. in view of Miller, mind and mental processes provide direction to human behavior and actions in a specific situation; while psychological problems not only disturb the state of mind rather behavior and expressions of the person as well (Miller, 1948). 


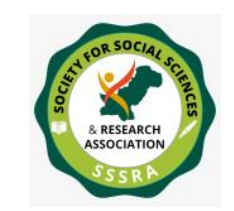

Pak. Journal of Int'L Affairs, Vol 4, Issue 3 (2021) Individual and conflict: a sociological analysis ...

Personality disorders negatively affect mental abilities, feelings and to a large extent behavior and expressions and give birth to psychological problems like stress, depression and anxiety that have inverse effects on family and social life of individual. In addition, the physiological effects of personality disorder include pessimistic worldview and fear of people and social situations that create boredom of social relations which arise negative personal tendencies like corporal violence, sexual abuse and criminal undertakings. In this situation, behavior of the person does not match with that of community members and resistance of any kind in response lead to conflict formation.

It is concluded from the study that, conflict formation is closely linked with negative personal characters internalized in individual either because of socialization, peer group, cultural influence or psychological and personal problems and their accompanying outcomes which distort normal social relations and arise negative energies in the person as well as in the people around. Initially, negative personal characters inversely affect mind and mental process of individual and then transform human behavior and expressions in the same direction that not only distort normal social relations rather end in conflict formation. The current research is only a part of much needed effort to analyze and point out the very contributing factors in conflict formation, but it is an important part that can help reduce a big deal of conflict formation if properly understood and implemented in one's life experience. 
Individual and conflict: a sociological analysis ...

\section{References}

Barash, D.P. and Webel, C.P. (2002) Peace and Conflict Studies (Thousand Oaks, CA: Sage Publications).

Baron, R.A. (1990), Conflict in organizations. In K. R. Murphy \& F. E. Saal (Eds.), Psychology in Organization: Integrating science and practice (pp. 197-216). Hillsdale, NJ: Erlbaum

Behfar, K. J., Peterson, R. S. [Randall S.], Mannix, E. A., \& Trochim, W. M. K. (2008). The critical role of conflict resolution in teams: A close look at the links between conflict type, conflict management strategies, and team outcomes. The Journal of Applied Psychology, 933(1), 170-188

Bendersky, C., \& Hays, N. A. (2012). Status Conflict in Group. Organization Science, 23(2), 323-340

Chuang, YS. \& Tzy-Ning, L. (2003), Interpersonal Conflict Styles and Employees Well Being Concern Study, International Business Department, Ching-Yun University

Deutsch, M. (1973). The resolution of conflict: Constructive and Destructive processes. New Haven: Yale University Press.

Dreu, C. K. W. \& Weingart, L. R. (2003). Task versus relationship conflict, team performance, and team member satisfaction: A meta-analysis. The journal of Applied Psychology, 88(4), 741-749. http://doi.org/10.1037/0021-9010.88.4.741

Elmagri, M.I. and Eaton, D. (2011), Identifying the Factors Causing Interpersonal Conflict in Organizations (Through Analyzing Secondary Data), The Built \& Human Environment Review, Volume 4, Special Issue 1,, P. 60

Fathali, M. II., \& Harr_e, Rom. (Eds) (2010) Words of Conflict, Words of War: How the Language We Use in Political Processes Sparks Fighting. Oxford, England: PRAEGER, an imprint of ABC-CLIO, LLC.

Fisher, R. (2000), Sources of Conflict and Methods of Conflict Resolution, International Peace and Conflict Resolution, School of International Service, The American University 
Pak. Journal of Int'L Affairs, Vol 4, Issue 3 (2021) Individual and conflict: a sociological analysis ...

George, J. M., \& Jones, G. R. (1997). Experiencing work: Values, attitude, and moods. Human Relations, 50(4), 393-416

Hermann, C., Jacobson, H. K. \& Moffat, A. S. (Eds) (1999). Violent conflict in the $21^{\text {st }}$ century causes, instruments \& mitigation. Chicago, IL: American Academy of Arts \& Sciences, Midwest Center

Hotepo, OM., Asokere, AS., Abdul-Azeez, IA. \& Ajemunigbohun, SA. (2010), Empirical Study of the Effect of Conflict on Organizational Performance in Nigeria, Business and Economics Journal, BEJ-15

Ilies, R., Johnson, MD., Judge, TA. \& Keeney, J. (2011), A within-individual study of interpersonal conflict as a work stressor: Dispositional and situational moderators, Journal of Organizational Behavior, 32, 44-64

Jehn, K.A. (1995), A multimethod examination of the benefits and detriments of intragroup conflict, Administrative Science Quarterly, Vol. 40, pp. 256-282

Jehn, K.A. and Bendersky, C. (2003), Intragroup conflict in organizations: A contingency perspective, Research in Organizational Behavior, Vol. 25, pp. 189-244.

Miller, N.E. (1948) "Classics in the History of Psychology" Psychological Review, 48, 337-342

Pawlak Z. (1998), An inquiry into anatomy of conflicts. Journal of Information Sciences, 109: 65-78.

Rahim, M. Afzalur. (2000): Managing conflicts in organizations (Westport, CT: Quorum Books 2000)

Williams, F. (2011), Interpersonal Conflict: The Importance of Clarifying Manifest Conflict Behavior, International Journal of Business, Humanities and Technology Vol. 1 No. 3; P. 149 